\section{Idiopathic pulmonary hemosiderosis mimicking iron deficiency anemia: a delayed diagnosis?}

\author{
Sultan Aydin Koker, ${ }^{1}$ Salih Gözmen, ${ }^{1}$ \\ Yeşim Oymak, ${ }^{1}$ \\ Tuba Hilkay Karapinar, ${ }^{1}$ Demet Can, ${ }^{2}$ \\ Sinan Genç, ${ }^{3}$ Raziye Canan Vergin ${ }^{1}$ \\ ${ }^{1}$ Division of Pediatric Hematology, \\ ${ }^{2}$ Division of Pediatric Allergy, ${ }^{3}$ Division \\ of Pediatric Radiology, Dr. Behçet Uz \\ Children's Hospital, İzmir, Turkey
}

\begin{abstract}
Idiopathic pulmonary hemosiderosis (IPH) is an uncommon chronic disorder in children. It is characterized by recurrent pulmonary hemorrhage and may result in hemoptysis and pulmonary insufficiency. The most common hematologic manifestation of IPH is iron deficiency anemia. The etiology of IPH is not known and its diagnosis may be difficult due to the variable clinical courses. The most helpful signs for identifying IPH are iron deficiency anemia and recurrent or chronic cough, hemoptysis, dyspnea, wheezing. We report here 5 pediatric cases of IPH presenting with iron deficiency anemia and without pulmonary symptoms. Mean corpuscular volume was low in all patients; iron was low in 4 out of 5 cases; total iron binding capacity was high in all of them; ferritin was low in 3 patients. At follow up, none of them had responded successfully to the iron therapy. Although they didn't present with pulmonary symptoms, chest radiographs incidentally revealed diffuse reticulonoduler shadows in all of them. Computed tomography revealed diffuse ground-glass opacities, consolidation, increased density. The diagnosis was confirmed by the detection of hemosiderinladen macrophages in bronchoalveolar lavage fluid and gastric aspirate. If patients with iron deficiency anemia don't respond to iron therapy, they should be examined for IPH. Chest radiographs should be taken even in absence of pulmonary symptoms. Early diagnosis is important for a timely management of IPH.
\end{abstract}

\section{Introduction}

Anemia is a disorder characterized by the reduction in the number of red blood cells and/or hemoglobin ( $\mathrm{Hb})$ level. ${ }^{1}$ Iron deficiency anemia (IDA) is the most common cause of childhood anemia. IDA is still a common public health problem affecting a large number of children and women in developing countries. It affects $24.8 \%$ of the World population. $^{2}$ The most common cause of IDA is a rapid growth of iron requirements due to insufficient iron intake and blood loss. ${ }^{3}$ Patients with IDA have taken oral elemental iron (3-4 mg/kg/day) as a therapy. Response to iron treatment is very important in children with IDA. When being refractory to iron treatment at follow up or when episodic erythrocyte transfusion have been need due to hemoglobin decreasing, idiopathic pulmonary hemosiderosis (IPH) should be considered as a differential diagnosis without pulmonary symptoms. Actually, IPH is an infrequent pulmonary disease characterized by a triad of hemoptysis, iron-deficiency anemia and diffuse parenchymal infiltrates owing to bleeding into the alveolar of pulmonary. ${ }^{4}$ However, the diagnosis of IPH have been delayed, because pulmonary hemorrhages and hemoptysis is rare in children and the absence of respiratory symptoms in children has been also canalized to look for other causes of IDA like cystic fibrosis, congenital heart diseases, malignancies, and gastrointestinal pathologies. ${ }^{5,6}$ We report 5 pediatric cases of IPH, who presented with IDA for a long time without having severe pulmonary findings.

\section{Case Report}

We have reported to clinical findings and laboratory of our five cases below (Table 1). Despite the patients had pallor, iron deficiency anemia at diagnosis, they had not pulmonary symptoms such as hemoptysis, dyspnea, wheezing. Three of them had cough. The common feature of all our patients is having not pulmonary symptoms and following for a long time due to iron deficiency anemia before determining to pulmonary hemosiderosis. Mean Corpuscular Volume (MCV) was low at all of them. Iron was low at four patients. Total Iron Binding Capacity was high at all of them. Ferritin was low at three patients.

Chest radiographs revealed diffuse reticulonoduler shadows in all patients. Computerized tomography (CT) revealed diffuse ground-glass opacities, consolidation, increased density (Figure 1). The diagnosis was confirmed by the detection of hemosiderin-laden macrophages in bronchoalveolar lavage fluid (BAL) and gastric aspirate.

Once the diagnosis of pulmonary hemo-
Correspondence: Sultan Aydin Koker, Department of Pediatrics, Dr. Behçet Uz Children's Hospital, İzmir, Turkey.

Tel.: +554.538 .3483$

E-mail: drsultanaydin@hotmail.com

Key words: Idiopathic pulmonary hemosiderosis, Iron deficiency anemia, Delayed diagnosis.

Contributions: the authors contributed equally.

Conflict of interest: the authors declare no potential conflict of interest.

Received for publication: 13 January 2017. Accepted for publication: 21 March 2017.

This work is licensed under a Creative Commons Attribution-NonCommercial 4.0 International License (CC BY-NC 4.0).

CCopyright S.A. Koker et al., 2017

Licensee PAGEPress, Italy

Hematology Reports 2017; 9:7048

doi:10.4081/hr.2017.7048

siderosis was confirmed, patients were administered oral prednisolone at a dose of $2 \mathrm{mg} / \mathrm{kg} /$ day for 2 weeks if they presented during acute phase. In addition, a milk free diet was recommended for all patients. Steroids were gradually tapered, if possible, over a period of 4 to 6 weeks after the initial 2 -week period of treatment. Minimum dose of steroid was maintained during having their normal hemoglobin value, follow up.

\section{Discussion}

Firstly, IPH, a rare pulmonary disorder, was described in 1931, as a triad of hemoptysis, iron deficiency anemia and diffuse parenchymal infiltrates on chest X-ray. ${ }^{7}$ While the incidence of IPH in children is $0.24-1.23$ case per million, the mortality rate of its is higher than $50 \%{ }^{8}$ Altogether, $80 \%$ of cases occur in children, most of them being diagnosed in the first decade of life. IPH commonly occurs in children below the age of 10 years; frequently between the ages of 1-7 years. ${ }^{7}$ The diagnosis of IPH is delayed due to showing the variable clinical presentation in children especially. ${ }^{9}$ According to the literature, diagnosis ages of our patients were quite too late. In the study by Kabra et al., the mean gap between onset of symptoms and diagnosis was 30 months. ${ }^{10}$.The passing time for diagnosis in our brief report was $36,12,6,14$ and 12 months, respectively. This delay in diagnosis may be due to absence of classical triad, an silent onset 
and lack of awareness about the disorder. Although the passing time for diagnosis in one of our patients was too short owing to having the usual triad of hemoptysis, iron deficiency anemia and reticulonoduler findings on chest X-ray. The diagnosis time of another was too late for having not classical triad. Clinical onset varies significantly from acute, fulminant hemoptysis, to chronic cough and dyspnea, repetitive hemoptysis, fatigue, or only asymptomatic anemia. ${ }^{11}$ In adults, the respiratory symptoms can be more pronounced, while in children failure to thrive and anemia (and less often hemoptysis) can be the presenting findings. ${ }^{12}$ In the study by Kabra et al., patients having the diagnosis of pulmonary hemosiderosis were determined cough (100\%), hemoptysis $(58 \%)$, and dyspnea (85\%); iron deficiency anemia (100\%); respectively (10). All of our patients had iron deficiency anemia. In addition, pulmonary findings were not significant in our patients.

The most laboratory abnormality was anemia, present in $100 \%$ patients. ${ }^{13}$ It is probably due to not only to the lack of hemoptysis, but to the fact that iron deficiency anemia may be the first and the only manifestation of IPH. ${ }^{14,15}$ In our patients, the atypical clinical manifestations included presenting with severe anemia are repeated blood transfusions and absence of hemoptysis in four of patients. Our patients had iron deficiency anemia as a only manifestations of IPH. The sideropenic (transferrin saturation $<40 \%$ ), microcytic ( $\mathrm{MCV}<80 \mathrm{fL}$ ) anemia is the result of diffuse alveolar hemorrhage. Plasma ferritin level can elevated because of the alveolar synthesis and release into the circulation and do not reflect the iron deposits of the body. ${ }^{15}$ In the our study, all of them had the decreased transferrin saturation and MCV. In contrary of literature, three of our patients had the

\section{hypoferritinemia.}

Pulmonary involvement may not been found clinically at the onset of IPH. Chest X-ray may present normally. ${ }^{16}$ Our patients demonstrated reticulonodular infiltrates on chest imaging, although they had not hemoptysis and pulmonary symptoms. Ground-glass opacities, patchy infiltrates, consolidation had also been detected at the thorax CT. The diagnosis of IPH is detected to hemosiderin-loaded macrophages into bronchoalveolar lavage (BAL) fluid, gastric lavage fluid or sputum. ${ }^{12}$ But the gold stan-
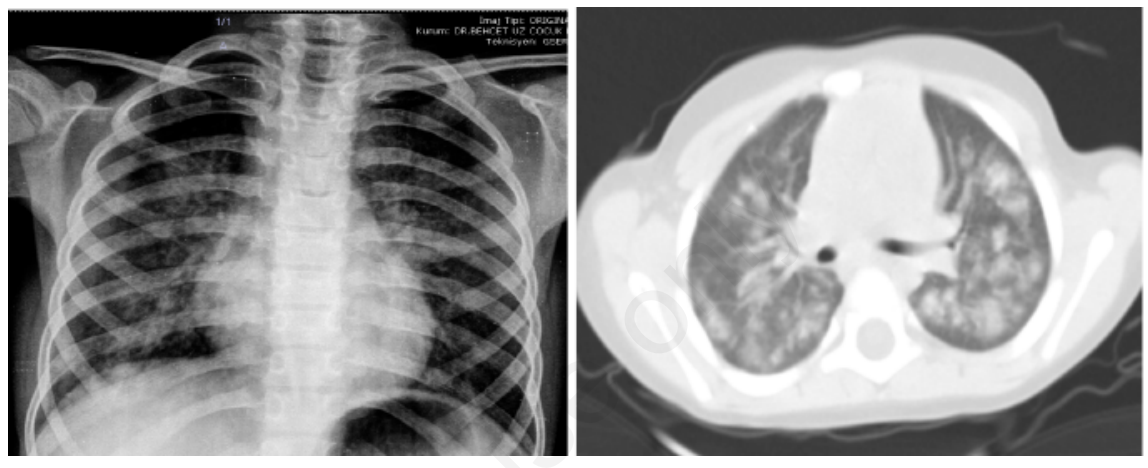

Figure 1. Chest imaging demonstrated reticulonodular infiltrates and thorax computed tomography showed ground-glass opacities, patchy infiltrates and consolidations.

Table 1. Clinical profile and laboratory of patients with idiopathic pulmonary hemosiderosis.

\begin{tabular}{|c|c|c|c|c|c|}
\hline & Case 1 & Case 2 & Case 3 & Case 4 & Case 5 \\
\hline Sex & Female & Male & Male & Female & Male \\
\hline Age at diagnosis (year) & 11 & 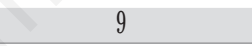 & 14 & 7 & 2 \\
\hline Hemoptysis & - & - & + & - & - \\
\hline Dyspnea/breathlessness & - & - & - & - & - \\
\hline Cough & + & - & + & - & + \\
\hline Fever & + & - & - & - & - \\
\hline Wheezing & - & - & - & - & - \\
\hline Pallor & + & + & + & + & + \\
\hline Jaundice & - & - & - & - & - \\
\hline Severe anemia & + & + & - & + & + \\
\hline Iron-deficiency anemia & + & + & + & + & + \\
\hline Time to diagnosis (months) & 36 & 12 & 6 & 14 & 12 \\
\hline $\begin{array}{l}\text { Laboratory } \\
\text { Hemoglobin }(\mathrm{g} / \mathrm{dL}) \\
\text { Mean corpuscular volume (fL) } \\
\text { Iron }(50-120 \mu \mathrm{g} / \mathrm{dL}) \\
\text { Total iron binding capacity }(110-370 \mathrm{ug} / \mathrm{mL}) \\
\text { Ferritin }(50-140 \mathrm{ng} / \mathrm{mL})\end{array}$ & $\begin{array}{c}7.3 \\
67 \\
8 \\
478 \\
105\end{array}$ & $\begin{array}{c}8.1 \\
61 \\
20 \\
528 \\
3.5\end{array}$ & $\begin{array}{c}10.7 \\
71 \\
34 \\
390 \\
18.8\end{array}$ & $\begin{array}{c}6.4 \\
73 \\
24 \\
399 \\
171\end{array}$ & $\begin{array}{c}7 \\
69 \\
102 \\
458 \\
10.5\end{array}$ \\
\hline On examination & Normal & Normal & Normal & Normal & Normal \\
\hline At diagnosis & $\begin{array}{l}\text { Hemosiderin-laden } \\
\text { macrophages } \\
\text { in gastriclavagefluid }\end{array}$ & $\begin{array}{l}\text { Hemosiderin-laden } \\
\text { macrophages in } \\
\text { bronchoalveolarlavage }\end{array}$ & $\begin{array}{l}\text { Hemosiderin-laden } \\
\text { macrophages in } \\
\text { bronchoalveolarlavage }\end{array}$ & $\begin{array}{l}\text { Hemosiderin-laden } \\
\text { macrophages in } \\
\text { bronchoalveolarlavage }\end{array}$ & $\begin{array}{c}\text { Hemosiderin-laden } \\
\text { macrophages in } \\
\text { bronchoalveolarlavage }\end{array}$ \\
\hline Chest X-Ray & Reticulonodular & Common cotton throw & Reticulonodular & Reticulonodular & Reticulonodular \\
\hline $\mathrm{Gr}$ & $\begin{array}{l}\text { round-glass opacities, } \\
\text { consolidation, } \\
\text { increased density }\end{array}$ & $\begin{array}{l}\text { Ground-glass opacities, } \\
\text { increased density }\end{array}$ & $\begin{array}{c}\text { Ground-glass opacities, } \\
\text { patchy infiltrates }\end{array}$ & $\begin{array}{l}\text { Ground-glassopacities, } \\
\text { acino-nodular infiltrates, } \\
\text { left lower lobe and upper } \\
\text { lobe consolidation }\end{array}$ & $\begin{array}{c}\text { Ground-glass opacities, } \\
\text { consolidation, } \\
\text { increased density }\end{array}$ \\
\hline
\end{tabular}


dard for diagnosis has been considered to be lung biopsy. ${ }^{17}$ First case of our patients had hemosiderin-loaded macrophages in gastric aspirate, while other of them had hemosiderin-loaded macrophages in bronchoalveolar lavage. In the present study gastric aspirate had a sensitivity of $30 \%$ while BAL had a sensitivity of $92 \%{ }^{12}$

Systemic corticosteroids are the first line treatment for acute alveolar hemorrhage. Long-term steroid therapy may also reduce morbidity and decrease mortality. ${ }^{4,12}$ In our patients, we decided to use prednisolone to control the acute findings. Especially, anemia of the our patients was improved with using steroid treatment.

\section{Conclusions}

In conclusion, the five pediatric cases admitted with iron deficiency anemia did not responded good to the iron therapy. However, they were successfully diagnosed with IPH in spite of not having pulmonary symptoms, due to the presence of hemosiderin-laden macrophages in BAL and gastric lavage fluid, and thanks to the radiological findings of chest X-ray and thorax CT.

We can therefore conclude that IPH must be investigated in patients with iron deficiency anemia who don't respond to iron therapy, despite having no pulmonary symptoms.

\section{References}

1. De LM, Pena-Rosas RJP, Cusick S. Hemoglobin concentrations for the diagnosis of anemia and assessment of severity; vitamin and mineral nutrition information system. Vol 11. Geneva: World Health Organization; 2011.

2. Benoist BD, McLean E, Egli I. Worldwide prevalence of anemia 19932005. Geneva: World Health Organization; 2008

3 . Tunç B. Iron deficiency anemia in children. Turkish J Pediatr Dis 2008;2:4357.

4 Kjellman B, Elinder G, Garwicz S, Svan H. Idiopathic pulmonary haemosiderosis in Swedish children. Acta Paediatr Scand 1984;73:584-5.

5. Kamienska E, Urasinski T, Gawlikowska-Sroka T, et al. Idiopathic pulmonary haemosiderosis in a 9-yearold girl. Eur J Med Res 2009;14:112-5.

6. Godfery S. Pulmonary hemorrhage/ hemoptysis in children. Pediatr Pulmonol 2004;37:476-84.

7. Heiner DC. Pulmonary hemosiderosis. In: Chernick V, Kendig EL (eds). Kendig's disorders of the respiratory tract in children. 5th ed. Philadelphia: WB Saunders; 1990. pp. 498-509.

8. Ohga S, Takahashi K, Miyazaki S, et al. Idiopathic pulmonary haemosiderosis in Japan: 39 possible cases from a survey questionnaire. Eur J Pediatr 1995;154:994-5.

9. Yao TC, Hung IJ, Wong KS, et al. Pitfalls in the diagnosis of idiopathic pulmonary haemosiderosis. Arch Dis Child 2002;86:436-8.

10. Kabra SK, Bhargava S, Lodha R, et al. Idiopathic pulmonary hemosiderosis: clinical profile and follow up of 26 children. Indian Pediatr 2007;44:333-8.

11. Soergel K, Sommers SC. Idiopathic pulmonary hemosiderosis and related syndromes. Am J Med 1962;32:499511.

12. Ioachimescu OC, Sieber S, Kotch A. Idiopathic pulmonary haemosiderosis revisited. Eur Respir J 2004;24:162-70.

13. Kiper N, Goemen A, Ozcelik U, et al. Long term clinical course of patients with idiopathic pulmonary hemosiderosis (1979-1994): prolonged survival with low dose corticosteroid therapy. Pediatr Pulmonol 1999;27:180-4.

14. Chen KC, Hsiao CC, Huang SC, et al. Anemia as the sole presenting symptom of idiopathic pulmonary hemosiderosis: report of two cases. Chang Gung Med J 2004;27:824-9.

15. Minkov M, Kovacs J, Wiesbauer P, et al. Severe anemia owing to occult pulmonary hemorrhage: a diagnostic pitfall. J Pediatr Hematol Oncol 2006;28: 467-70.

16. Taytard J, Nathan N, De Blic J, et al. New insights into pediatric idiopathic pulmonary hemosiderosis: the French RespiRare(®) cohort. Orphanet J Rare Dis 2013;8:161.

17. Nuesslein TG, Teig N, Rieger $\mathrm{CH}$. Pulmonary haemosiderosis in infants and children. Pediatr Respir Rev 2006;7:45-8. 